\title{
Presentation of Playing the Stars
}

\section{Toby MacLennan}

Abstract. This talk reports on a performance of the planetarium event Singing the stars with sculptures, which was performed at the H.R. Macmillan Planetarium in Vancouver and the Seneca College Planetarium in Ontario. Subsequent performances were done at the Art Gallery of Ontario, P.S.1, New York City, the 10th International Sculpture Conference, Toronto, and The National Gallery of Canada. It was reviewed in the Village Voice, Arts Canada, The New Art Examiner, Vanguard Magazine, and CBC Radio:

Out of the belly of Vancouver's H.R. Macmillan Planetarium, the star-making machine rises to the star chamber, carrying three musicians with their instruments, and three sculptures. Atop each sculpture is an overhanging frame of five wooden bars, which acts as a musical score. Lights go down over the planetarium audience. Stars move across the sky. Only the constellations and the luminous bars atop the sculptures are visible. Swept up by the grandeur of the constellations, the musicians look up through the bars atop their sculptures and give a concert playing the stars. The concert is inspired by a story from my book, Singing the Stars. A village of people has lost the power of night, which once resided within them. The people attempt to lure the night back with the help of sculptures, which will enable them to play and sing the stars. They hope that, lured by the music, the night will come close to their faces, and bits of darkness will fall into their ears, eyes and mouths and gradually fill up their bodies with the night sky.

\section{Singing the Stars}

Occasionally, a curious feeling strikes me that something forgotten is trying to remember itself through me. It's as if I'm out strolling on my day off from teaching and a bird flying close overhead lets out a sudden cry. I stop in my tracks. Everything freezes. I look up. Nothing is there. Days after one of these feelings occurred I sat down and wrote the story, Singing the Stars. ${ }^{1}$

\footnotetext{
${ }^{1}$ Toby MacLennan, Singing the Stars (Toronto: Coach House Press, 1983). All photos in this paper are taken by Toby MacLennan. Video excerpts from Singing

Toby MacLennan, 'Presentation of Playing the Stars' eds. Nicholas Campion and Rolf Sinclair, Culture and Cosmos, Vol. 16 nos. 1 and 2, 2012, pp. 443-450. www.CultureAndCosmos.org
} 


\section{Presentation of Playing the Stars}

The story reveals a few days in the lives of people in a remote, imaginary village, where everyone seems to be suffering from some lingering malady. And you know how small towns are - everyone knows what everyone else is doing. The gossiping was the same all over personal complaints, mainly. 'All I want to do is sleep', one man said. Another exclaimed, 'I remember at night lying on the beach for hours. The sky was filled with more stars than spaces between them. I felt like the stars were inside me. Where has that feeling gone?'

One woman claimed, 'I used to look up at the night sky for so long I forgot to come home for dinner when my mother called. Why doesn't that happen anymore?' After many confessions, someone finally drew a conclusion, 'It seems clear - we have all lost the power of night'. Gossip about the lost night quickly spread, and, believing that recovering the power of night was the cause of their shared malady, this was the plan: each man, woman and child would build a sculpture with a frame on top that contained bars that functioned as a musical score (Figure 1).

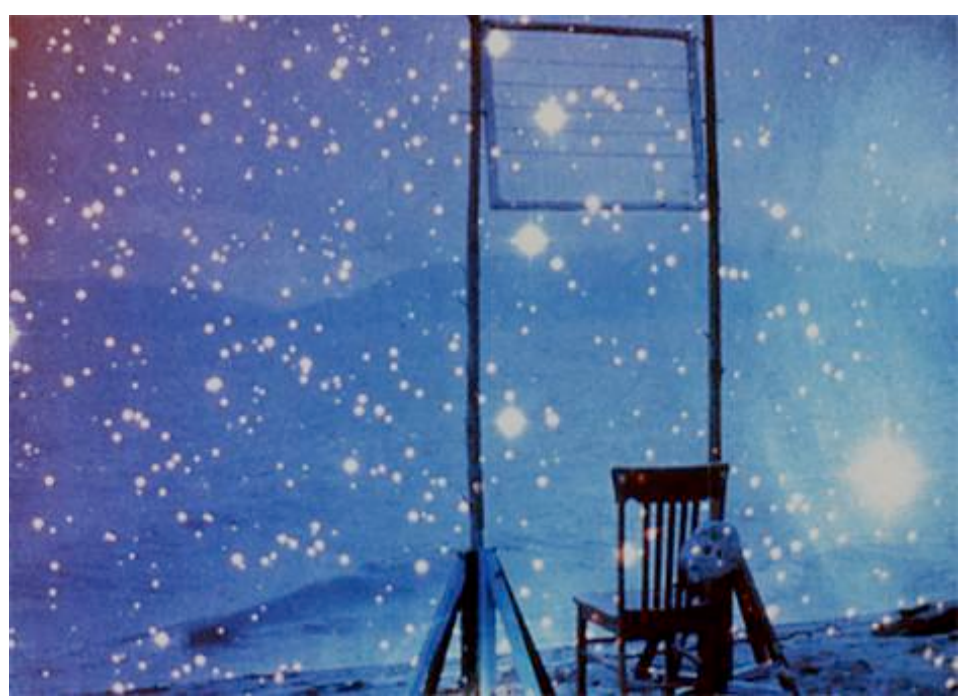

Figure 1. Score sculpture

One clear night, together, they would bring their sculptures up to the highest mountain near their village and set them up. Each of them would

the Stars, performed at the Art Gallery of Ontario in Toronto can be seen on my website: http://www.tobymaclennan.com. 
then look up at the stars falling in the note spaces of the sculptures' score and sing or play the stars as notes.

The next day sounds of hammers and saws singing through the air filled the village, energy the village had not known for some time. On the first clear night filled with stars, everyone bundled up their sculptures and drove up to the highest point in the village.

Altogether they looked up at the sky through the score atop their sculpture and began to sing and play the stars falling into the note spaces of their score. Soon you could see them all on the mountaintop. Spread out all over the darkened landscape were the simple outlines of thousands of figures singing and playing the stars, while the sky, drawing near to them, began to chip off in bits and pieces and fall into their eyes and mouths and ears and fill up their bodies with the night.

I was living in Vancouver and teaching sculpture at the University of British Columbia. After writing the story, Singing the Stars, I constructed a musical stand much like I had imagined the sculpture to be in the story (Figure 2).

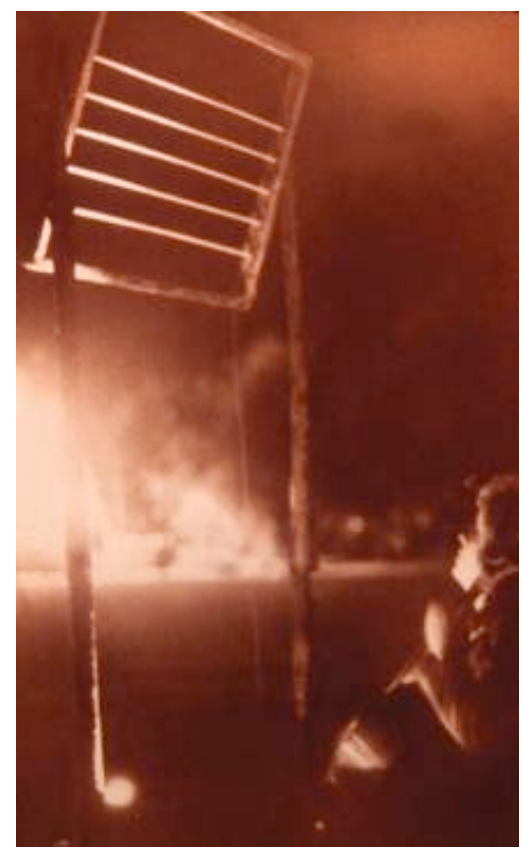

Figure 2. Musical stand

One clear night, Natalie Green (a visual artist and a cellist) and I loaded the sculpture into my truck and drove up into the Vancouver Mountains. 


\section{Presentation of Playing the Stars}

As we set up the sculpture and prepared for Natalie to play the stars, we became a bit nervous (Figure 2). We were all alone, high in the mountains and far from any city. Stars filled the sky and surrounded us with a stillness I have never known. Natalie sat poised with her cello, ready to play the stars as notes. Her eyes shifted to me and she said, 'If I start playing the stars and something by Beethoven comes out, I'm really going to freak out'.

Following our adventure on the mountain, I built more sculptures that allowed people to sing and play the stars, and performed Singing the Stars at the H. R. MacMillan Planetarium in British Columbia (Figure 3).

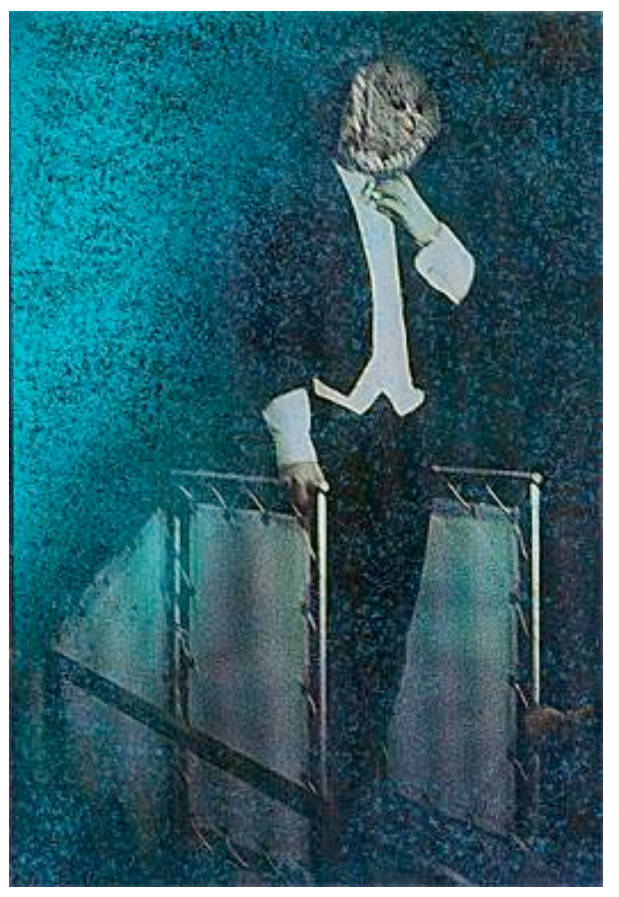

Figure 3. The lights in the planetarium dim

Into the circular chamber of the Planetarium, a man wearing a tuxedo and a mask is wheeled in as if on a ceremonial staircase. The man stops just ahead of the seated audience, and waits.

Slowly out of the belly of the planetarium, the star-making apparatus rises up into the Star Chamber carrying Natalie with her cello and a man and his harp. Both musicians stand in front of a sculpture made out of tree branches. 


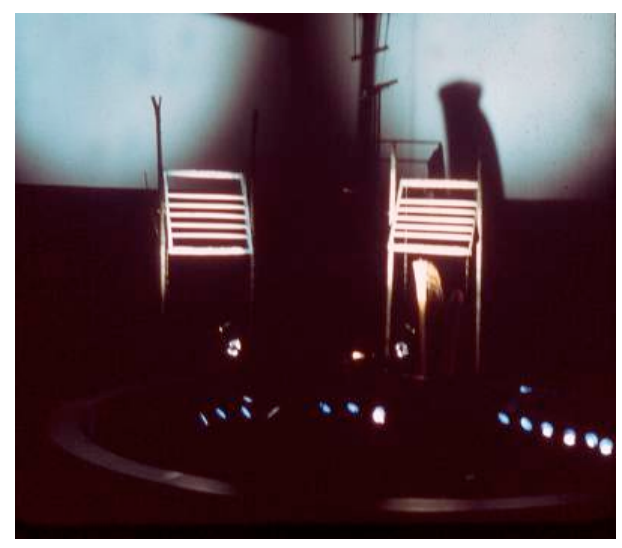

Figure 4

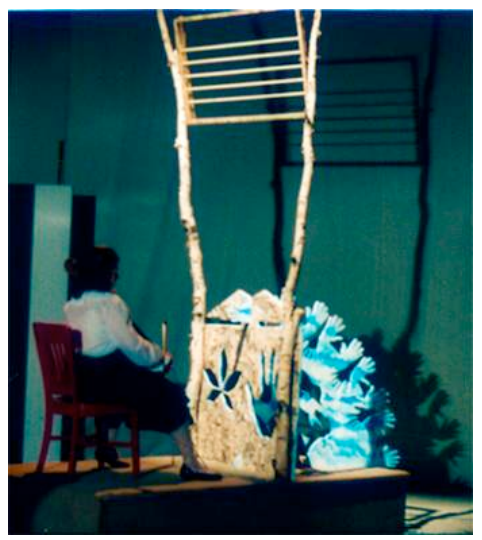

Figure 5

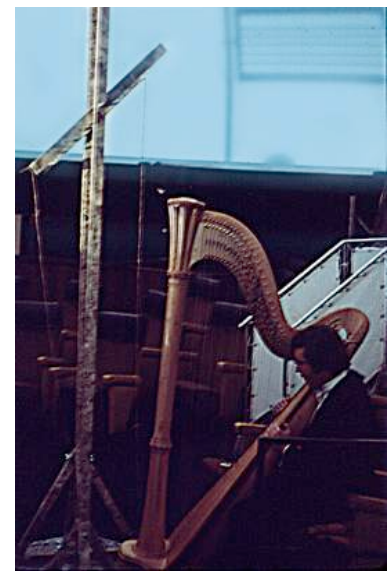

Figure 6

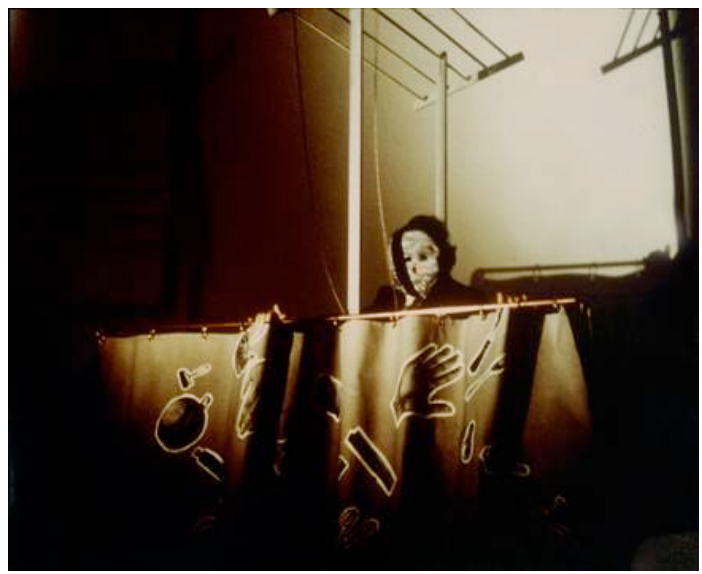

Figure 7

Between the cellist and the harpist sits a strange box the size of a bathtub. It reminds one of a large toy. A curtain surrounding the box is painted with images of a chair, a stone, light bulb, key, shell, spoon, hat, and a hand, arranged in the form of constellations. Wooden poles on either side of the box hold up a frame with five bars (Figures 4 to 7). A steering wheel inside the box can turn the box $360^{\circ}$ and a rope, attached to the frame above, allows the occupant to tilt the frame at any angle. The musicians turn to the man in the mask waiting on the staircase. He walks onto the stage and over to the box, climbs in, and lies down. He closes the curtains around him so he cannot be seen. The box clanks awkwardly as the man turns it 360 degrees (Figure 8). 


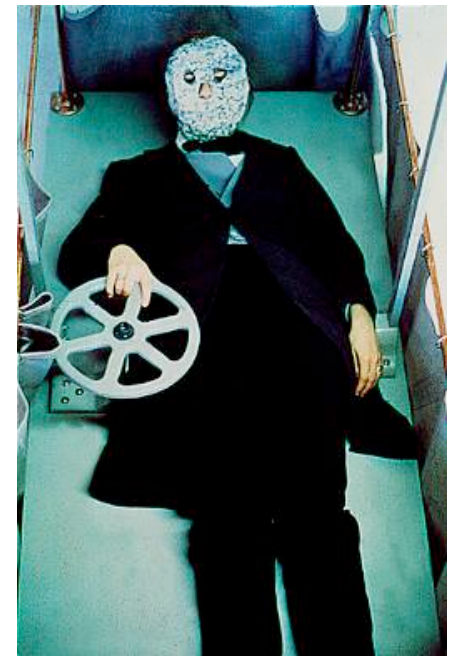

Figure 8

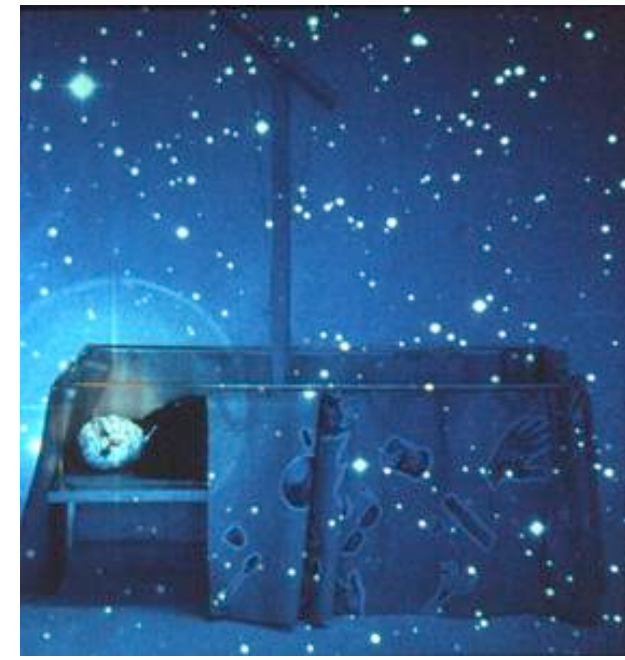

Figure 9

The frames atop the sculptures are painted with phosphorescent paint. As the lights dim in the Star Chamber the frames of the sculptures begin to glow a ghostly blue (Figure 9). Swept up by the grandeur of the constellations, the musicians look up through the bars atop their sculptures and give a concert singing and playing the stars.

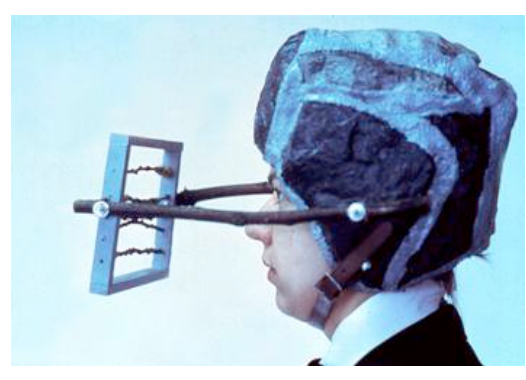

Figure 10

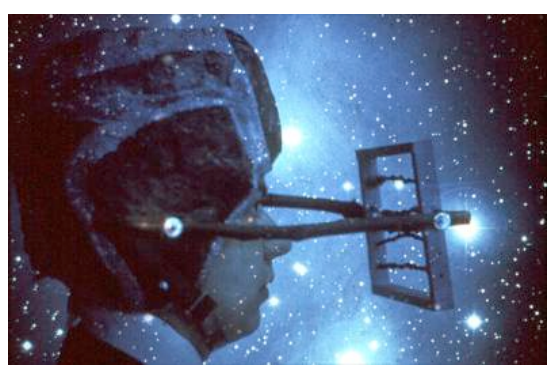

Figure 11

Following this same performance in the Seneca College Planetarium in Toronto, I created a series of elaborate sculptures for singing the stars, which included sculptures worn by singers and musicians (Figures 10 to 15). These events were performed in galleries using multiple star projections to envelop the space and the performers. 


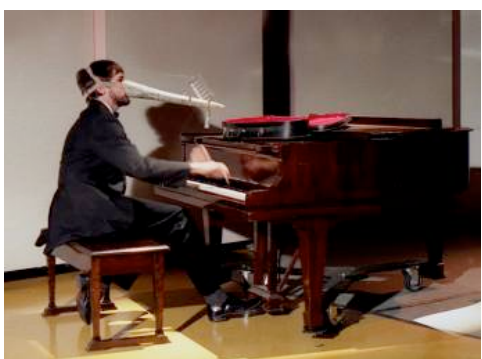

Figure 12

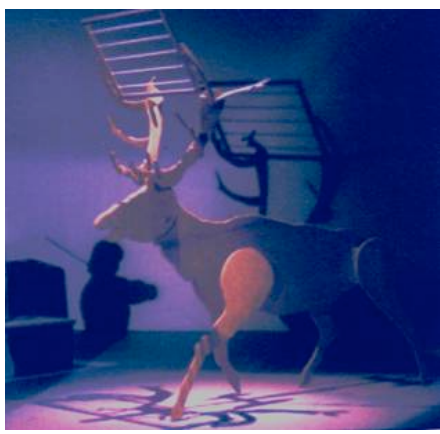

Figure 14

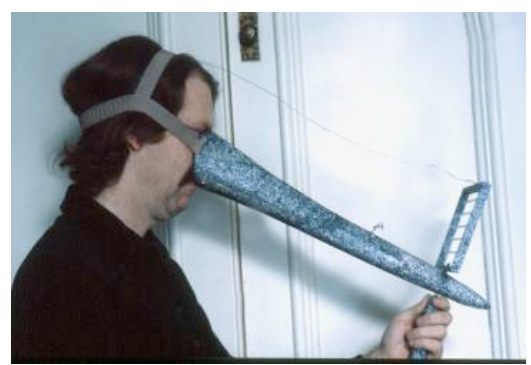

Figure 13

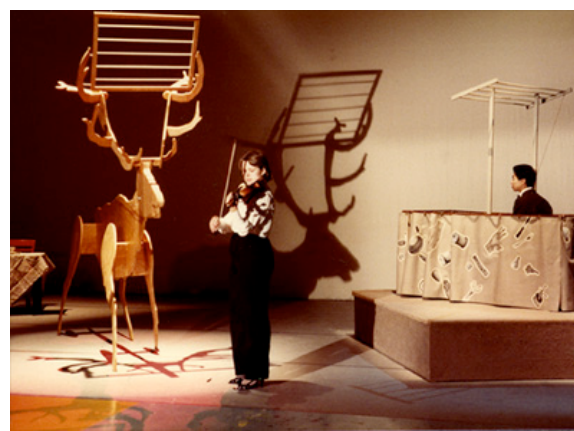

Figure 15

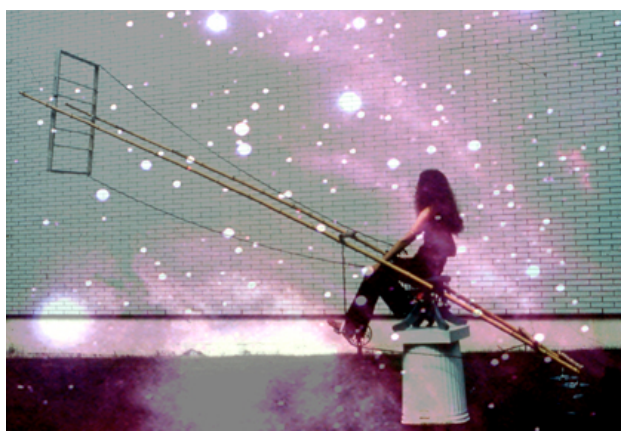

Figure 16

In this sculpture a woman singer sits atop a swivel chair (Figure 16). The chair allows the sculpture to turn 360 degrees. By peddling a pair of bicycle pedals, the frame at the end of the sculpture can be raised or lowered to change the view of the stars.

In a Performance at the Art Gallery of Ontario, a man wearing a helmet climbs upon a table, looks through the musical score attached to 


\section{Presentation of Playing the Stars}

his helmet, and sings the dishes and silverware on the table as they appear in the note spaces of his score (Figure 17).

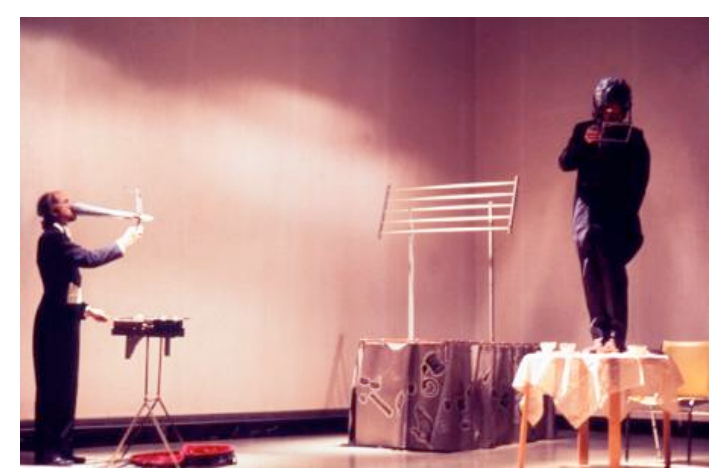

Figure 17

At the same time a man across the gallery sings the table and the man on the table as they fall into the note spaces of the musical score on the end of his nose sculpture (Figures 18 and 19).

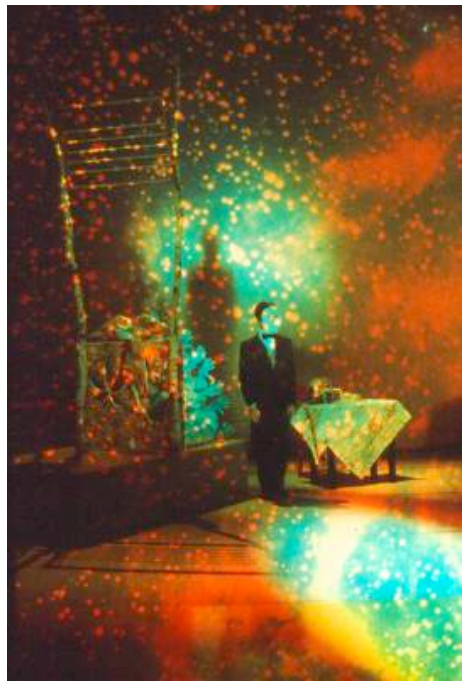

Figure 18

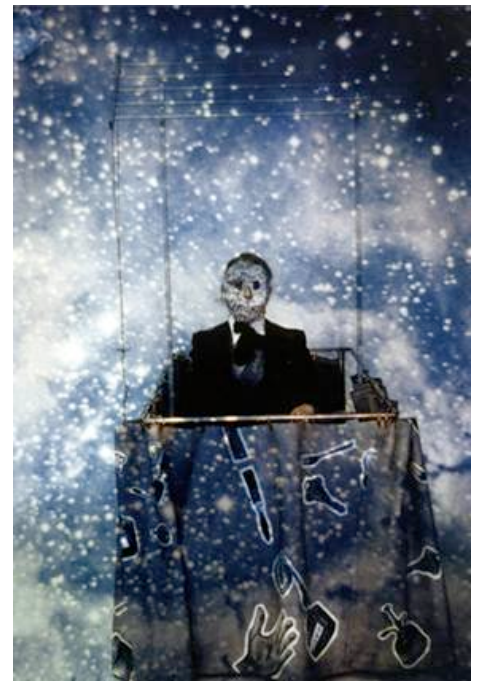

Figure 19 